\title{
SPECIFICS OF INVESTIGATION OF HORIZONTAL WELLS WITH FHF
}

\section{. . ильф нов}

\section{E. F. Gilfanov}

или $л$

лючевые слов : гидродин мические исследов ния; многозонный гидр влический р зрыв пл ст ; горизонт льн я скв жин; яинейный приток; р ди льный приток

Key words: hydrodynamic studies; formation multi-zone hydraulic fracturing; horizontal well; linear influx; radial influx

ри р зр ботке месторождений нефти и г з применение горизонт льных скв жин ( ) все больше ст ло привлек ть вним ние нефтепромысловиков во всем мире.

ел ние бурить вместо вертик льных скв жин появилось, когд специ листы поняли, что площ дь поверхности горизонт льного ствол всегд н много больше площ ди поверхности · оэтому приток в должен быть кр тно в L/h p з больше, чем в (L - длин, $\mathrm{h}$ - толщин пл ст $)$. олгое время ре лиз цию т кого прием увеличения добычи нефти и г з сдержив ло неумение строить скв жины с горизонт льным стволом, проходящим в продуктивной толще пород, т кже высок я стоимость бурения.

овсеместное применение н ч лось в середине 80-х годов прошлого столетия, вн ч ле 21-го век т кое бурение приобрело м ссовый х р ктер. т ло ясно, что бурение позволяет повысить эффективность р зр ботки месторождений не только 3 счет улучшения процессов приток жидкости к скв жине. еперь ктивно обсужд ются вопросы и охв т пл ст $\mathrm{p}$ зр боткой, и возможности одновременно выр б тыв ть несколько пл стов, и профил ктики и борьбы с $з$ воднением и т. д.

дн ко при ре лиз ции н пр ктике проектов бурения р зличных (или нескольких ) возникл проблем отсутствия поним ния природы движения флюидов в сложных геологических условиях, при новых способ х вскрытия продуктивных отло- 
жений, в ри нты которых ст новятся многообр зными. первый пл н выдвиг ются проблемы изучения процессов фильтр ции н основе гидродин мических исследов ний.

целом, необычный феномен р звития техники связ н с тем, что теоретическ я 6 п по проблеме движения флюидов в пл сте к отст ет от ре лизов нных проектов по бурению многоствольных .

н стоящее время есть только простое объяснение поведения д вления в при путем оценки формиров ния плоскоп р ллельного течения в ближних зон х и p ди льного в уд ленных (рис. 1), пок нет решений для более сложных конфигур ций течений, порожденных горизонт льными ствол ми.

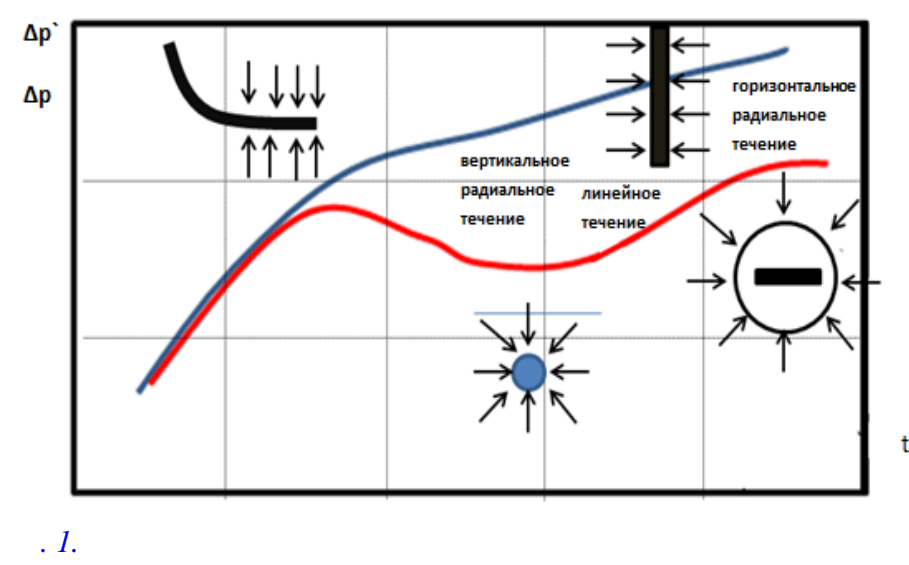

и гностический гр фик производной д вления выявляет з кономерности движения флюид с трещин ми искусственного происхождения. орб производной н гр фике $\log -\log$ х р ктеризует влияние ствол скв жины. риток жидкости к горизонт льной скв жине выглядит т к: течение билинейное (плоскоп р ллельное) с уклоном $\mathrm{i}=1 / 4$, н клон прямой $\mathrm{i}=1 / 2$ - линейное течение поток жидкости, прямолинейный уч сток $\mathrm{i}=0 \mathrm{x}$ р ктеризует потоки уд ленной ч сти пл ст .

римеры $з$ меров д влений в горизонт льных скв жин х пок зыв ют, что 3 редким исключением н пр ктике можно получить кривые д влений в виде, пок 3 нном н рис. 1. к пр вило, конфигур ция з пис нной н пр ктике отр ж ет другие эффекты, доминирующие при проявлении пл ст в р зличные периоды з меров д влений, созд ющие условия, близкие к линейному, р ди льному или другим вид м течений. то связ но с тем, что в чистом виде их встретить невозможно, и всегд они сопровожд ются некоторыми сильно влияющими ф ктор ми (неоднородностью в пл сте, слоистостью, влиянием р боты соседних скв жин и пр.). оэтому всегд необходимо исследов ть объект изучения с оценкой возможного проявления дополнительных ф кторов (геологических и технологических). иже приведен пример исследов ния ряд горизонт льных скв жин н месторождении юменского евер .

опытном уч стке месторождения пробурено 15 н клонно н пр вленных скв жин, в том числе 4 н гнет тельные и 3 горизонт льные, скв. 778 с четырьмя фр кпорт ми, (786) с одним , (792) без

рис. 2 пок 3 ны х р ктеристики для скв жин 778 (пилотный), 777 и 782. л ст толщиной 8-15 м является нефтен сыщенным, слоисто неоднородным. иже н ходится водон сыщенный горизонт с перемычкой 4-8 м. бъект р зр ботки - пл ст ${ }_{1}^{1}$ от нижележ щего, водоносного пл ст $1_{1}^{2}$ отделяет пл ст ргиллитов мощность 6-7 м.

собенностью бурения вертик льных скв жин было то, что все они з пуск лись в эксплу т цию обводненными. большинстве скв жин выполнялись в период их освоения. н лиз причин т кого обводнения скв жин пок з л, что вод во всех вертик льных скв жин х появлял сь в продукции ср зу, когд было исключено поступление 3 к чив емой воды н гнет тельными скв жин ми, зн чит вод появлял сь вследствие перетоков из нижележ щих водоносных горизонтов из-з нек чественного цементиров ния. после проведения увеличение в продукции воды можно объяснить прорывом трещин в водон сыщенные горизонты, что и приводило к повышению обводненности (т бл.). 


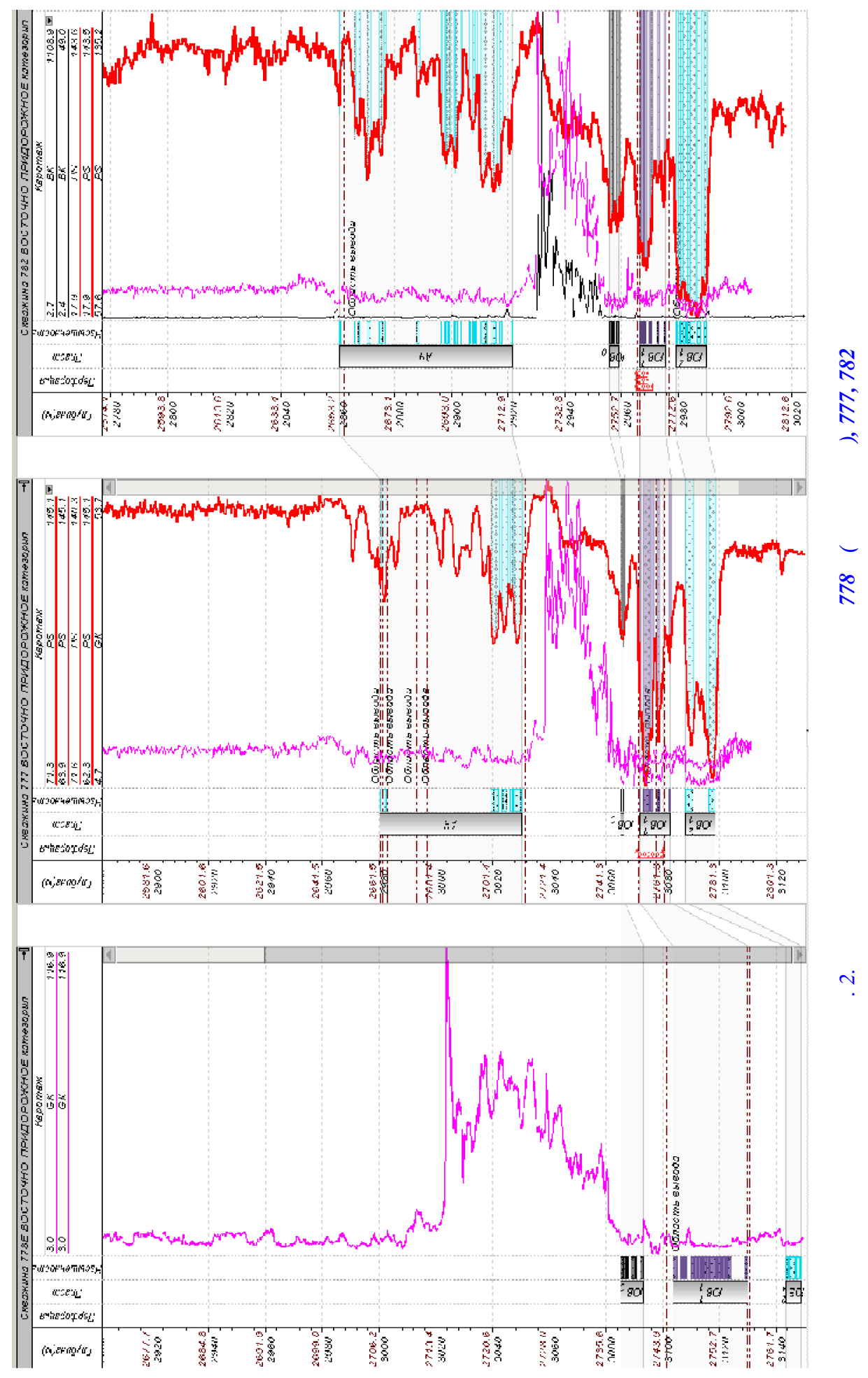

№ 4, 2016 
ромысловые $х$ р ктеристики р боты скв жинн р ссм трив емом уч стке

\begin{tabular}{|c|c|c|c|c|c|}
\hline кв жин & зн чение & $\begin{array}{c}\text { ебит / приемистость } \\
\text { жидкости, т/сут }\end{array}$ & $\begin{array}{c}\text { ебит нефти, } \\
\text { т/сут }\end{array}$ & $\begin{array}{c}\text { бвод- } \\
\text { ненность, } \%\end{array}$ & $\begin{array}{c}\text { т } \\
\text { проведения }\end{array}$ \\
\hline 472 & обыв ющ я & 19 & 10 & 48 & 27.08 .2009 \\
\hline 624 & обыв ющ я & 6,8 & 0,1 & 99 & $\begin{array}{c}25.04 .2010 \\
\text { (ост новлен } \\
12.11 .2012)\end{array}$ \\
\hline 773 & гнет тельн я & 64,5 & - & 100 & 20.01 .2010 \\
\hline 777 & обыв ющ я & 11,9 & 4,3 & 64 & 09.01 .2011 \\
\hline 778 & обыв ющ я & 38,5 & 22,5 & 41,2 & 20.06 .2011 \\
\hline 782 & гнет тельн я & 196,4 & - & 100 & 01.04 .2011 \\
\hline 783 & гнет тельн я & 51,8 & - & 100 & 02.07 .2011 \\
\hline 786 & обыв ющ я & 15,4 & 6,4 & 58 & 13.11 .2011 \\
\hline 787 & обыв ющ я & 18,4 & 7,3 & 61 & 13.12 .2011 \\
\hline 792 & обыв ющ я & 11,2 & 10,4 & 7 & нет \\
\hline 839 & обыв ющ я & 47,8 & 7,3 & 85 & 14.12 .2010 \\
\hline
\end{tabular}

р ктеристики добычи продукции из горизонт льных скв жин приведены н рисунк х $3-5$.

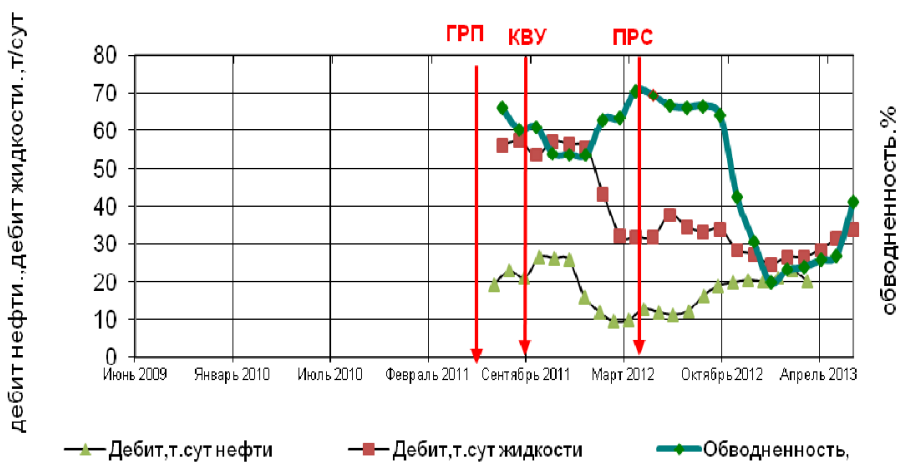

ис. 3. обыч нефти из скв. 778

к видно, скв жины 778 и 786 ср зу были з пущены в эксплу т цию с высокой обводненностью - 60 и $40 \%$. то же время скв. 792 имел входную обводненность д же н много ниже н ч льной обводненности вертик льных скв жин. то прямое свидетельство отсутствия конт кт с нижележ щим водоносным горизонтом.

риведенный кр ткий н лиз промысловой информ ции по эксплу т ции вертик льных и горизонт льных скв жин позволяет более уверенно выполнить н лиз и интерпрет цию результ тов гидродин мических исследов ний

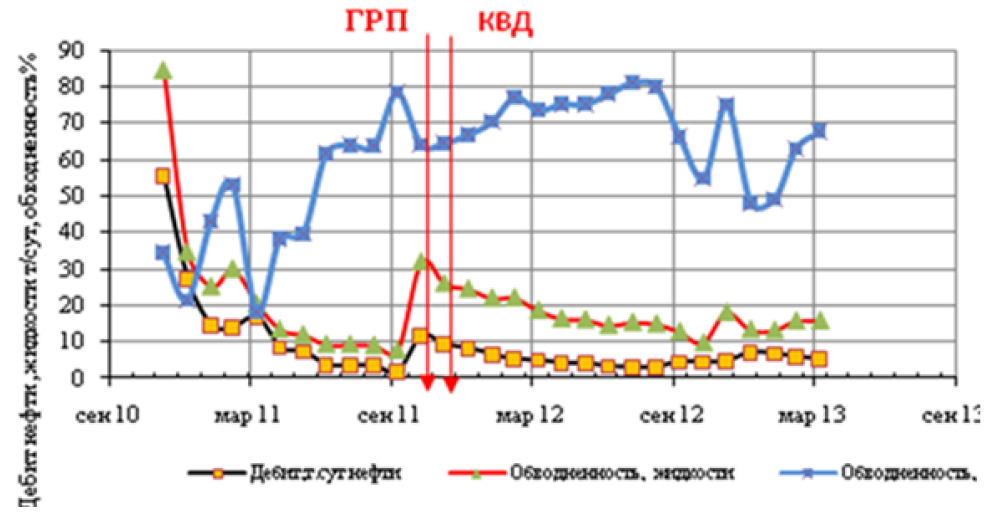

ис. 4. обыч нефти из скв. 786 


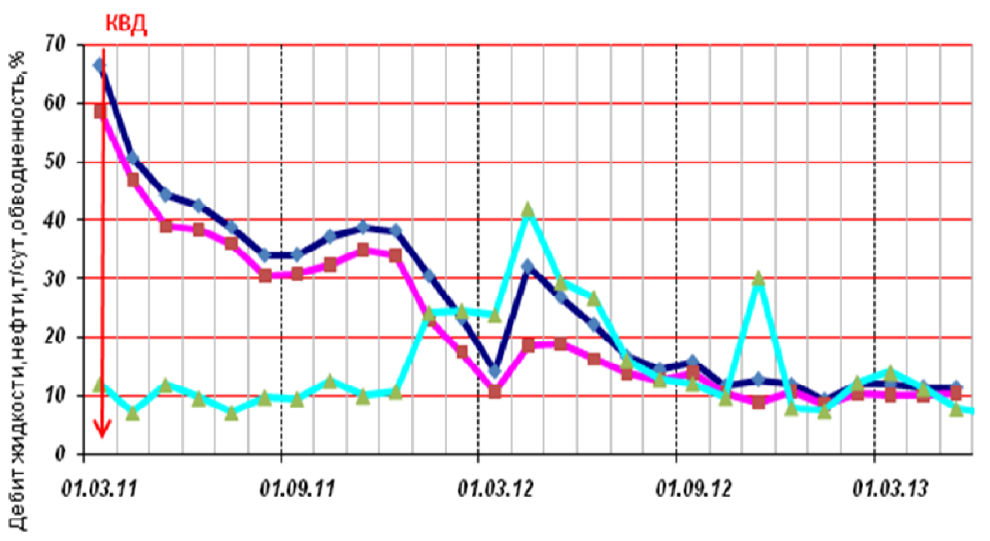

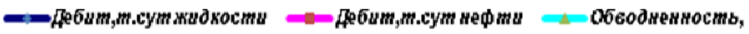

ис. 5. обыч нефти из скв. 792

р фики , полученные при исследов нии скв жин 778 (с 4 ), 786 (1

), 792 (без ) в $\log -\log$ шк л х (совмещенные гр фики -t и производной $\mathrm{dP} / \mathrm{dt}-\mathrm{t})$, предст влены н рис. 6.

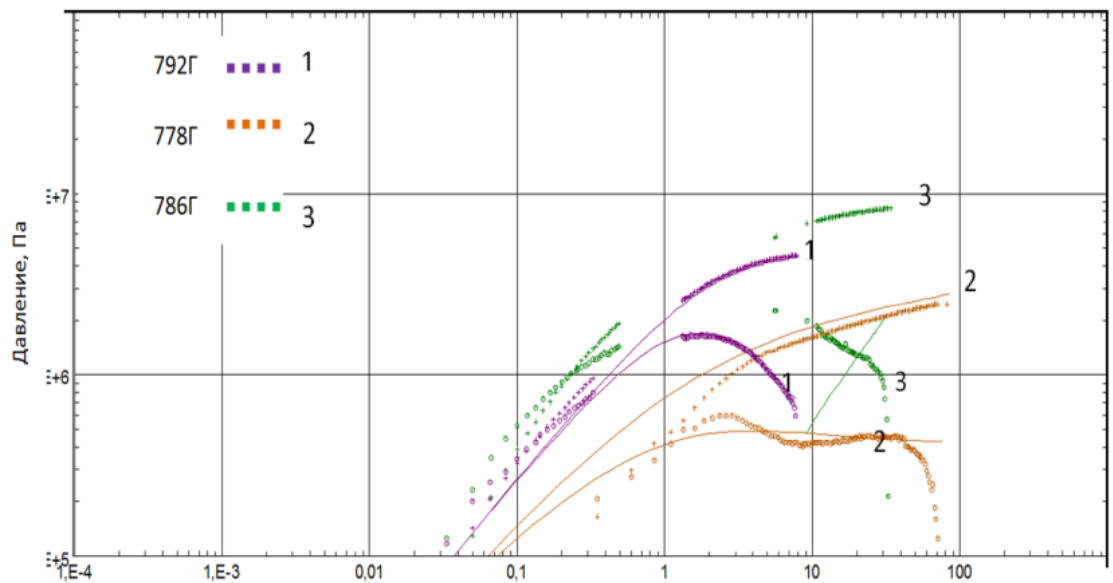

ис. 6. езульт ты исследов ния скв. 778 (4 фр к-порт ), 786 (1 фр к-порт), 792

к видно, гр фики , з пис нные в горизонт льных скв жин х, совершенно не соответствуют предст вленным н рис. 1 «кл ссическим»

скв. с 778 р ди льный приток проявляется примерно через 8 ч сов, хотя при ст нд ртных з мер х н ч льный «горб»н н н ходится в предел х не более 1-го ч с . скв. 786 «емкостные эффекты» 3 к нчив ются через 30 ч сов, в скв жине 792 з 8 ч сов еще не з кончился этот эффект.

оличество 3 к ч нного пропп нт в трещину в среднем сост вило 8 т. ероятно, что в скв жин х с нижний кр й трещины достиг ет кровли пл ст (водоносный), и охв т дрениров нием горизонт льного уч стк происходит ч стично, приток воды - из нижнего пл ст $1^{2}$

идно, что в скв. 778 возникло р нее близкое к р ди льному течение жидкости ( с углом н клон $\mathrm{i}=0,15$ ). о есть, плоскоп р ллельного течения не возникло. p ди льные потоки доминируют, что возможно в том случ е, если одн из трещин (из четырех) р спростр нил сь в нижний водоносный пл ст. оэтому скв жин н $60 \%$ р бот л с водой. 
одтверждением того, что одн из трещин поп л в водоносный горизонт, служ т результ ты н лиз гр фиков 3 к чки пропп нт при (рис. 7), по одному из которых видно резкое снижение д вления, «излом», н гр фике з писи (точк ) после ост новки 3 к чки р бочих гентов. нное предположение подтвержд ется и при обр ботке основного тест при проведении (рис. 8).

гр фике производной н блюд ется р ди льный приток н 12-й минуте, свидетельствующий о ст билиз ции д вления в окрестностях трещины, н клон производной отриц тельный, что говорит о выходе в зону постоянного д вления, то есть в нижний водоносный пл ст.

оризонт льн я скв. 792 , где не проводилось , р бот ет почти без воды - $7 \%$. о из-з кр тковременной з писи (восемь ч сов) - н ди гностическом гр фике отобр зился только процесс влияния емкости ствол скв жины.

кв жин 786 с , н против, обводнен н $58 \%$. есмотря н то, что з мер д вления выполнялся в течение 35 ч сов, после з вершения процесс иск ж ющие влияния скв жины ни плоскоп р ллельного, ни р ди льного течения не обн ружены. триц тельный н клон кривой в конечной своей ч сти $(\mathrm{i}=-1,1)$ свидетельствует о возможном проявлении гр ниц.

ким обр зом, из д нного н лиз следует, что интерпрет ция $\quad$ в $\quad$ н основе ст нд ртных методов невозможн, т к к к ре льные процессы фильтр ции явно отлич ются от кл ссических (см. рис. 1).

еобходимо моделиров ние процессов фильтр ции при обр ботке результ тов.

сли применить известные прогр ммные средств тип Saphir, то необходимо выделять н ди гностическом гр фике те уч стки, где можно с уверенностью объяснить доминирующее проявление пл ст для д нного интерв л з мер. тем вести н стройку н основе соответствующей модели только в предел х выделенного Уч СТК .

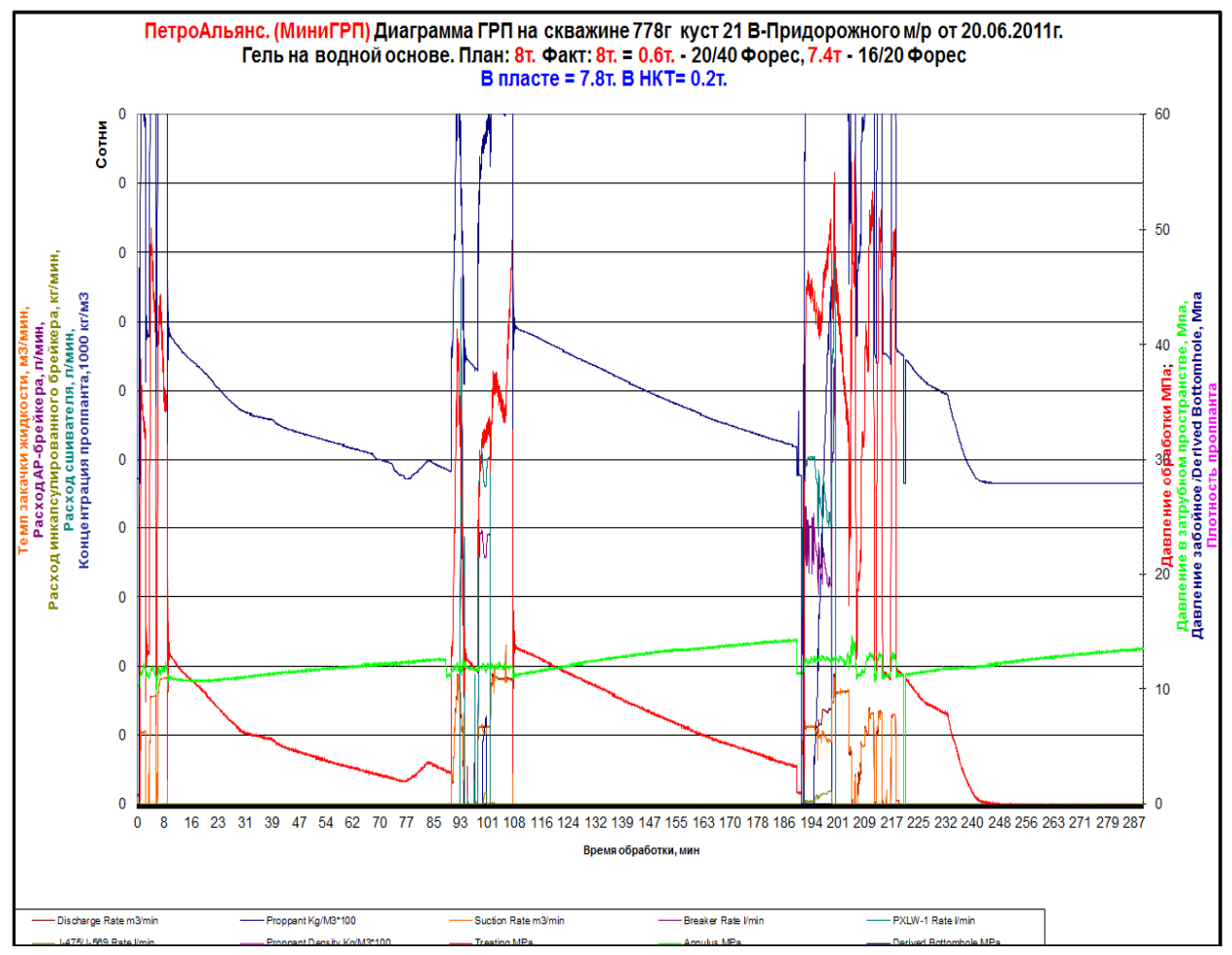

ис. 7. р фик проведения 


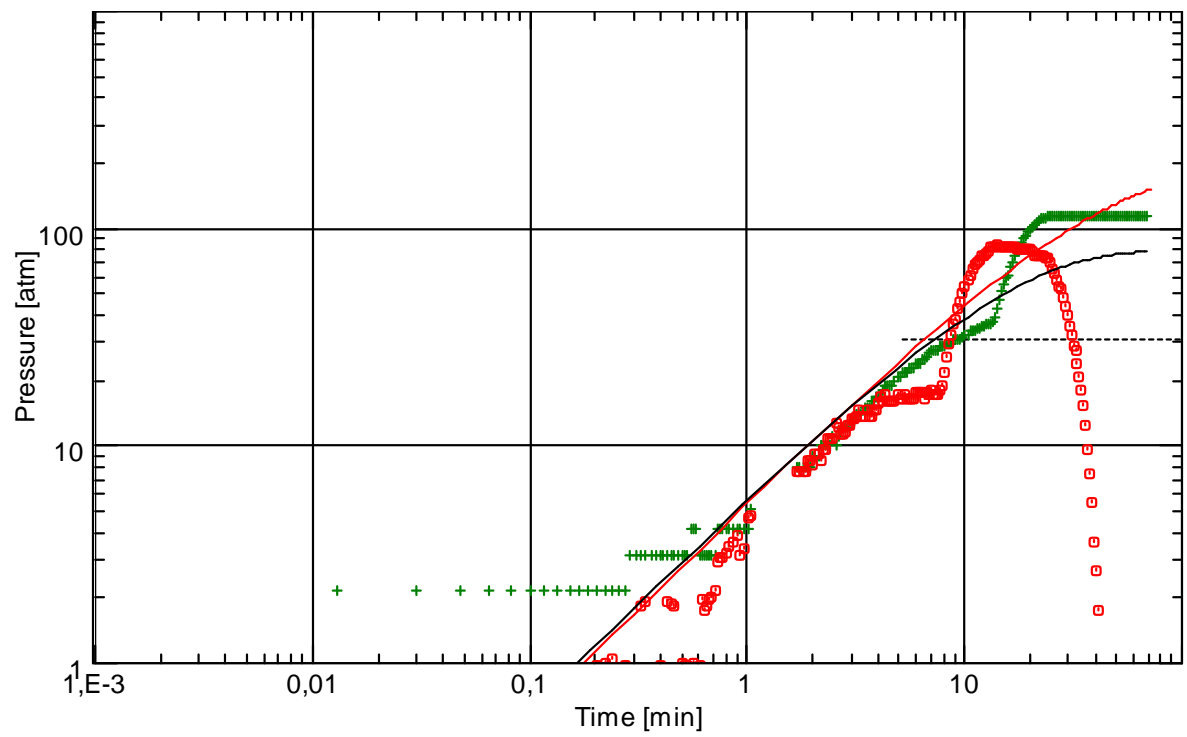

ис. 8. р фик депрессии и производной

при основном тесте

, 1-й nopm

ким обр зом, при пл ниров нии

в горизонт льных скв жин х необходимо учитыв ть н личие мощности пл ст, глинистой перемычки между объектом p зр ботки и водоносным горизонтом.

ри м ломощных непрониц емых пропл стк х необходимо проведение огр ничением р звития трещины ниже подошвы пл ст

роведение

позволяет контролиров ть эффективность

ведения об вторе

ильф нов ду рд у тович, з ведующий

л бор торией методического сопровождения технологии гидродин мических исследов ний $и$ интерпрет иии, фили $\Omega$ нжиниринг»

2. юмень, gil60@mail.ru

\section{Information about the autho}

Gilfanov $\boldsymbol{E} . \boldsymbol{F}$., head of the laboratory of methodical support of the technology of hydrodynamic studies and interpretation, affiliate of $L L C$ «LUKOL-

Engineering», «KogalymNIPIneft» in the town of Tyumen, phone: 89123947564, e-mail: geogil60@mail.ru 